\title{
Arabic coffee with two doses of cardamom: effects on health biomarkers in healthy women
}

\author{
Maha M Badkook*, Randa M Shrourou \\ Department of Food and Nutrition, King AbdulAziz University, Jeddah, Saudi Arabia \\ Email address: \\ mmbadkook@kau.edu.sa(M. M Badkook),randa.shrourou@hotmail.com(R. M Shrourou)
}

\section{To cite this article:}

Maha M Badkook, Randa M Shrourou. Arabic Coffee with Two Doses of Cardamom: Effects on Health Biomarkers in Healthy Women. International Journal of Nutrition and Food Sciences. Vol. 2, No. 6, 2013, pp. 280-286. doi: 10.11648/j.ijnfs.20130206.13

\begin{abstract}
Background: Arabic coffee is a form of boiled unfiltered coffee rich in diterpenes, components shown to raise cholesterol. Cardamom, a component of Arabic coffee, has been traditionally used for its medicinal properties. This study investigates the effects of daily consumption of Arabic coffee with two different doses of cardamom on blood pressure, lipids, heart, and liver function biomarkers. Materials and Methods: Healthy adult females $(\mathrm{n}=36)$ were divided in three groups. Each was given daily $500 \mathrm{ml}$ Arabic coffee, either with no cardamom (3:0, Control), or with one proportion of cardamom (3:1, ACLC), or with two proportions of cardamom (3:2, ACHC) 5 days/week, for a period of 4 weeks. Fasting blood was withdrawn at baseline, and end of intervention. Serum was analyzed for lipid profile, C-reactive protein (CRP), heart, and liver enzymes. Blood pressure was measured at the beginning and end of intervention. Results: TC was elevated in ACLC group, while TC and LDL-C increased in ACHC group. GGT significantly decreased in both groups. Coffee consumption with both cardamom doses showed no differences in blood pressure, lipids, heart and liver enzymes, or CRP compared to non-cardamom Arabic coffee. Conclusion: Daily consumption of $500 \mathrm{ml}$ of Arabic coffee with regular or high doses of cardamom might be a risk factor for CVD due to elevation of TC and LDL-C especially with the high cardamom dose, despite its nil effect on blood pressure and inflammation, and beneficial effect on liver GGT enzyme.
\end{abstract}

Keywords: Arabic Coffee, Cardamom, Blood Pressure, Cardiovascular, Inflammation

\section{Introduction}

Coffee is the leading worldwide beverage after water. It is the second largest traded commodity worldwide after petroleum and it accounts for US\$10 billion annually [1]. In the kingdom of Saudi Arabia (KSA), it is estimated that $1.6 \mathrm{Kg}$ of coffee is consumed per capita per year [2]. The form of coffee highly consumed in KSA is primarily Arabic coffee. It is a type of boiled unfiltered coffee that seems to be rich in constituents which might exert unprecedented health effects. The major constituents of coffee that have been highly investigated and reported to have potential health impact are caffeine, chlorogenic acid, cafestol, and kahweol [1]. The stimulant effect of coffee is due to its caffeine content. Caffeine gives most people a temporary energy boost and elevates mood. In addition, the form of coffee bean processing and the method of coffee preparation affect the proportion of its final constituents, and thus its health effects. Cafestol is a molecule present in coffee and is a potent cholesterol-elevating compound.The concentration of cafestol in a coffee drink is influenced by the brewing method. Boiled coffee (Scandinavian and Turkish style) contains the highest concentrations, whereas instant and drip filtered contain negligible amounts [3]. Kahweol, a structurally similar compound, also in coffee was found to cause a rise in cholesterol concentrations. A meta-analysis of 14 randomized controlled trials examining the effect of coffee consumption on serum cholesterol concentrations found that the consumption of boiled coffee dose-dependently increased serum total and LDL cholesterol concentrations, while the consumption of filtered coffee resulted in very little increase in serum cholesterol [4]. However, concerns about the potential health risks of coffee and caffeine consumption raised by epidemiological research in the past were likely exacerbated by associations between high intakes of coffee and unhealthy behaviors, such as cigarette smoking and physical inactivity [5]. Recently, coffee consumption has been associated with reductions in the risk of several chronic diseases $[6,7]$. The antioxidants present in coffee are useful in lowering the risk of coronary heart disease. Chlorogenic acid improves the antioxidative status of the 
body and reduces LDL oxidation [8].

Arabic coffee is a form of brewed, unfiltered coffee. It is a significant source of the two fat soluble constituents, cafestol and Kahweol. Arabic coffee is mainly a mixture of lightly roasted green coffee beans with cardamom. Cardamom belongs to the ginger family (Zingiberaceae).The main constituents in cardamom are antioxidants such as tocopherol, phenolic acids, indole-3-carbinol, and volatile organic compounds [9- 11]. Cardamom has been highly recommended as an ailment for diverse disorders such as digestion, asthma, bronchitis, cardiac disorders, diarrhea, nausea, cataracts, and for strengthening the nervous system [10].

The fact that Arabic coffee is an unfiltered type of coffee, and is a mixture of two major compounds, coffee beans and cardamom, both of which have shown controversial health effects, raises queries about its impact on health. To the best of our knowledge, no previous studies have addressed the consumption of Arabic coffee with different doses of cardamom in terms of its effect on lipid profile, blood pressure, C-reactive protein, cardiovascular, and liver enzymes.

\section{Materials and Methods}

\subsection{Subjects}

This study was conducted abiding by the Helsinki Declaration on ethical principles for medical research involving human subjects. Healthy adult females $(n=36)$ aged (18-40) years, who were non-smokers and non-alcoholic, were recruited from king Abdul-Aziz University, Jeddah, Saudi Arabia. They were either non-coffee drinkers, or if they were coffee drinkers, they were asked to refrain from drinking coffee for at least eight hours before the start of the experiment as the biological half-life for coffee in healthy subjects is 5.7 hours [12]. Participants were asked to restrict their consumption of foods and beverages rich in caffeine, cardamom, and any supplement containing caffeine or cardamom. Only those participants with no hypertension and dyslipidemia were eligible to participate in the study. Participants were divided into 3 groups, first group: Control group $(n=10)$ were given $500 \mathrm{ml}$ of freshly prepared Arabic coffee without cardamom (3:0). Second group $(n=13)$ were given $500 \mathrm{ml}$ of freshly prepared coffee with cardamom in the proportion 3 coffee: 1 cardamom (3:1, ACLC). Third group: $(n=13)$ were given $500 \mathrm{ml}$ of freshly prepared coffee with cardamom in the proportion 3coffee:2 cardamom $3: 2$, ACHC). All Coffee types were administered 5 days a week for 4 weeks. Fasting blood samples were drawn at baseline, and after 4 weeks of intervention. Fresh blood was centrifuged at 2500 r.p.m. for $15 \mathrm{~min}$ and serum aliquots were divided into $2 \mathrm{ml}$ eppendorf tubes and stored in a deep freezer $\left(-80^{\circ} \mathrm{C}\right)$ for later analysis. Blood pressure was measured using a sphygmomanometer (LAICA, Italy) at the beginning and end of the study.

\subsection{Inflammation Biomarker}

C-reactive protein (CRP) was analyzed according to Tietz (1986) using Enzyme Linked Immunoassay (ELISA) [13] (Immage 800, Beckman coulter Co.; CA, USA).

\subsection{Cardiovascular Enzymes}

Creatine kinase (CK) and Lactate dehydrogenase (LDH) were analyzed according to Siekmann et al., (2002) using a spectrophotometer (Dimension XPAND PLUS, Germany) [14].

\subsection{Liver Enzymes}

Alanine transaminase (ALT) was analyzed according to Bergmeyer et al., (1978),[15] Aspartate transaminase (AST) (Bergmeyer et al., (1977),[16] Total protein (TP) was analyzed according to Smith (2001),[17] Gamma glutamyltranspeptidase (GGT) was analyzed according to Shaw et al.,(1983),[18] and Total Bilirubin (TBI) was analyzed according to Doumas et al., (1973) [19]. All tests were performed by a spectrophotometer (Dimension XPAND PLUS, Germany).

\subsection{Statistical Analysis}

Data for blood pressure, lipid profile, CRP, liver and heart enzymes were analyzed using the statistical package SPSS version 16. Paired comparison t-test of independent samples was used to test the different before and after intervention. Analysis of Variance test (ANOVA) and post-hoc tests (LSD and Tamhane) were used to analyze differences between groups.

\section{Results}

\subsection{Effect of Arabic Coffee on Blood Pressure and Serum Lipids}

This study aimed to investigate the dose-dependent effects of coffee with/without two doses of cardamom in healthy adult females aged 18-40 years five days a week for a period of four weeks. Arabic coffee consumption, with and without cardamom, did not change blood pressure before and after intervention as indicated by the paired comparison t-test (Table 1). Also, the ANOVA test did not show significant differences in blood pressure between the two intervention groups, or between the intervention groups and the control group post-intervention (Table 2).

As for serum lipids, the paired comparison t-test indicated a significant elevation $(\mathrm{p}=0.02)$ in $\mathrm{TC}$ in the ACLC group after intervention compared to pre-treatment level (Fig. 1). Also, in the ACHC group, both TC and LDL-C significantly increased after intervention compared to pretreatment level (Fig. 2). The ANOVA test indicated that TC was significantly lower in the ACLC group than the control group, and LDL-C was lower in the ACHC group compared to the control group at the end of the experiment. 
However, no significant difference was observed in HDL-C or TG compared to the control group at the end of intervention. (Table 2)

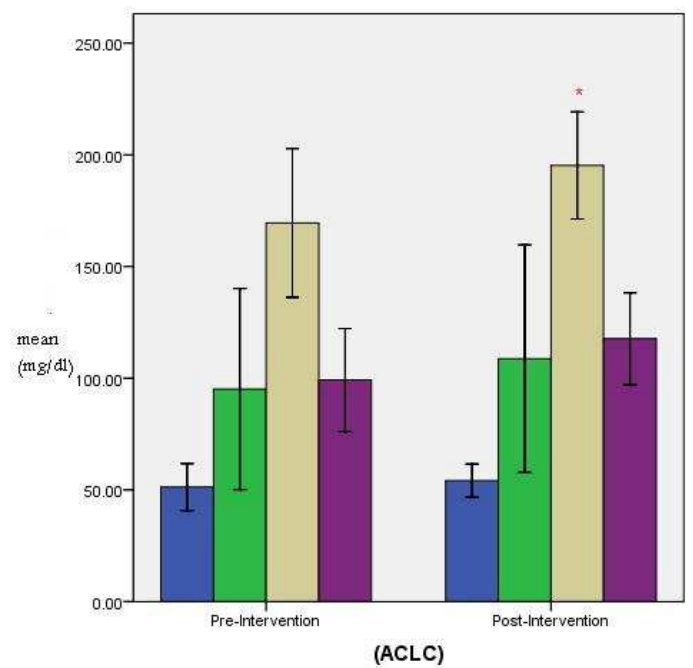

Figure 1. Mean serum lipid profile concentrations for pre and post coffee consumption in group 2 ACLC $(n=13) *$ represents significant difference for TC compared to pre-treatment level ( $p \leq 0.05)$. Abbreviations: $H D L-C-$ high-density lipoprotein cholesterol; TG- Triglycerides; TC- Total cholesterol; LDL-C-low-density lipoprotein cholesterol.

\subsection{Effect of Arabic Coffee on Liver Enzymes}

The paired comparison t-test showed a significant reduction in GGT enzyme activity $(\mathrm{p}=0.02)$ in both the second group $(36.63+7.46 \mathrm{U} / \mathrm{L}$ vs. $30.13+4.52 \mathrm{U} / \mathrm{L})$; and third group $(28.80 \pm 7.13 \quad \mathrm{U} / \mathrm{L} \quad v s .21 .90 \quad \pm 5.67 \quad \mathrm{U} / \mathrm{L})$ compared to pre-treatment levels (Table 3). However, there was no alteration in the activity of other liver enzymes as indicated in the mean concentrations ALT, AST, TP and TBI.

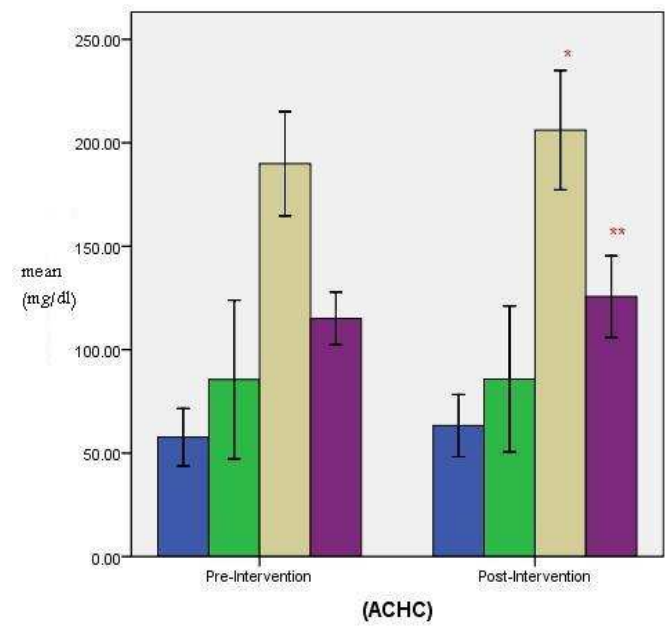

Error Bars: $95 \% \mathrm{Cl}$

Figure 2. Mean serum lipid profile concentrations for pre and post coffee consumption in group $3(A C H C)(n=13) *$ represents significant difference for TC compared to pre-treatment level $(p \leq 0.05)$.** represents significant difference for $L D L$ compared to pre-treatment level ( $p \leq 0.05)$.

Table 1. The effect of Cardamom in Arabic coffee on blood pressure and serum lipids before and after intervention

\begin{tabular}{|c|c|c|c|c|c|c|}
\hline \multirow{2}{*}{ Group } & \multicolumn{2}{|l|}{ BP (mm HG) } & \multirow{2}{*}{$\begin{array}{l}\text { TG } \\
\mathrm{mg} / \mathrm{dl}\end{array}$} & \multirow{2}{*}{$\begin{array}{l}\text { TC } \\
\mathrm{mg} / \mathrm{dl}\end{array}$} & \multirow{2}{*}{$\begin{array}{l}\text { HDL-C } \\
\mathrm{mg} / \mathrm{dl}\end{array}$} & \multirow{2}{*}{$\begin{array}{l}\text { LDL-C } \\
\mathrm{mg} / \mathrm{dl}\end{array}$} \\
\hline & DIAST & SYST & & & & \\
\hline \multicolumn{7}{|l|}{ Control } \\
\hline Pre-intervention & $69.29 \pm 10.67$ & $116.00 \pm 13.86$ & $93.14 \pm 39.26$ & $197.29 \pm 19.53$ & $49.86 \pm 17.73$ & $128.77 \pm 13.28$ \\
\hline Post-intervention & $73.14 \pm 11.32$ & $122.71 \pm 18.06$ & $96.00 \pm 41.02$ & $204.57 \pm 38.27$ & $50.57 \pm 18.74$ & $134.80 \pm 28.01$ \\
\hline \multicolumn{7}{|l|}{ ACLC } \\
\hline Pre-intervention & $75.00 \pm 17.22$ & $118.62 \pm 19.52$ & $95.13 \pm 53.87$ & $169.50 \quad 39.83^{\mathrm{a}}$ & $51.25 \pm 12.57$ & $99.23 \pm 27.51$ \\
\hline Post-intervention & $79.50 \pm 13.35$ & $119.50 \pm 17.35$ & $108.75 \pm 60.92$ & $195.25 \pm 28.70^{\mathrm{a}}$ & $54.13 \pm 8.90$ & $117.70 \pm 24.58$ \\
\hline \multicolumn{7}{|l|}{ АCHC } \\
\hline Pre-intervention & $67.60 \pm 11.16$ & $106.80 \pm 10.87$ & $81.50 \pm 48.73$ & $171.50 \pm 65.86^{\mathrm{b}}$ & $59.90 \pm 18.45$ & $115.11 \pm 16.55^{\mathrm{a}}$ \\
\hline Post-intervention & $71.10 \pm 6.44$ & $108.20 \pm 10.17$ & $85.80 \pm 49.27$ & $206.10 \pm 40.32^{b}$ & $63.30 \pm 21.04$ & $125.64 \pm 27.57^{\mathrm{a}}$ \\
\hline
\end{tabular}

Results are expressed as mean \pm SD. Data are analyzed by Paired Comparison t-test. ${ }^{\mathrm{a}, \mathrm{b}}$ represent significant differences before and after intervention within the group $(\mathrm{p} \leq 0.05)$.

Abbreviations: BP, Blood Pressure; TG, Triglycerides; TC, Total Cholesterol ; HDL-C, high-density lipoprotein cholesterol; LDL-C, low-density lipoprotein cholesterol. ACLC, Arabic coffee with low cardamom; ACHC, Arabic coffee with high cardamom. 
Table 2. Dose-response effect of Cardamom in Arabic coffee on blood pressure and serum lipids between groups at the end of the experiment

\begin{tabular}{|c|c|c|c|c|c|c|}
\hline \multirow{2}{*}{ Group } & \multicolumn{2}{|c|}{ BP(mm HG) } & \multirow{2}{*}{$\begin{array}{c}\mathrm{TG} \\
\mathrm{mg} / \mathrm{dl}\end{array}$} & \multirow{2}{*}{$\underset{\mathrm{mg} / \mathrm{dl}}{\mathrm{TC}}$} & \multirow{2}{*}{$\begin{array}{l}\text { HDL } \\
\mathrm{mg} / \mathrm{dl}\end{array}$} & \multirow{2}{*}{$\begin{array}{c}\mathrm{LDL} \\
\mathrm{mg} / \mathrm{dl}\end{array}$} \\
\hline & DIAST & SYST & & & & \\
\hline Control & $73.14 \pm 11.32$ & $122.71 \pm 18.06$ & $96.00 \pm 41.02$ & $204.57 \pm 38.27^{\mathrm{a}}$ & $50.57 \pm 18.74$ & $134.80 \pm 28.01^{\mathrm{a}}$ \\
\hline ACLC & $79.50 \pm 13.35$ & $119.50 \pm 17.35$ & $108.75 \pm 60.92$ & $195.25 \pm 28.70^{\mathrm{a}}$ & $54.13 \pm 8.90$ & $117.70 \pm 24.58$ \\
\hline ACHC & $71.10 \pm 6.44$ & $108.20 \pm 10.17$ & $85.80 \pm 49.27$ & $206.10 \pm 40.32$ & $63.30 \pm 21.04$ & $125.64 \pm 27.57^{\mathrm{a}}$ \\
\hline
\end{tabular}

Results are expressed as mean \pm SD. Data are analyzed by ANOVA test. Abbreviations: BP, Blood Pressure; TG, Triglycerides; TC, Total Cholesterol; HDL-C, high-density lipoprotein cholesterol; LDL-C, low-density lipoprotein cholesterol. ${ }^{a}$ represents significant differences between intervention group and the control group $(\mathrm{p} \leq 0.05)$.

\subsection{Effect of Arabic Coffee on Cardiovascular Enzymes and Subclinical Inflammation}

The paired t-test results indicated that there was an increase in the activity of the $\mathrm{CK}$ and $\mathrm{LDH}$ enzymes post-treatment compared to pre-treatment levels, but the increase was not significant at $(\mathrm{p} \leq 0.05)$. No significant difference was observed in C-reactive protein (CRP) concentrations post-treatment for all groups (Table4).

\section{Discussion}

Few studies have been conducted on Arabic coffee consumption, and those were exclusively done on animals. To our knowledge, this is the first study which measures the impact of Arabic coffee with two different doses of cardamom on serum lipids, hypertension, and biomarkers of cardiovascular and liver functions in humans.

Arabic coffee is a form of brewed, unfiltered coffee. It is a significant source of the two fat soluble constituents, cafestol and kahweol. These two compounds tend to raise cholesterol [20, 21]. In this study the consumption of Arabic coffee with either one dose or two doses of cardamom for four weeks significantly raised TC concentration compared to baseline level. In addition, LDL-C level was elevated in the group with two doses of cardamom. These effects might have been due to both the brewing of coffee and the cardamom added in the coffee. In accordance with these findings, one study measuring the effect of Arabic coffee on se rum lipids of rats indicated a significant increase in TC, LDL-C and TG [22].

Another study indicated that the intake of coffee, especially unfiltered coffee, significantly contributed to the increase in TC, LDL-C, and TG [23]. Cardamom alone has been shown, in rats, to cause a significant increase in all parameters of lipid profile TC, TG, LDL-C, while HDL-C was lower than the respective mean values of the control [24]. Such findings implicate that since unfiltered coffee and cardamom, when administered each by itself, lead to a rise in TC, LDL-C and TG, might follow that Arabic coffee, which is a mixture of both unfiltered coffee with cardamom, would lead to the rise in TC and LDL-C.

The effect of Arabic coffee on blood pressure (BP) did not show any effect. Contrary to our finding, the study of coffee effect on blood pressure and cardiovascular disease in hypertensive individuals, caused an acute increase in BP in the first hour lasted $\geq 3$ hour. This contrast could be explained by the fact that the subjects in this study were healthy, non- hypertensive people. Also, the rise of BP in the study of Mesas et al., (2011) was temporary [25].

The enzyme lactate dehydrogenase, also known as lactic acid dehydrogenase, or ( $\mathrm{LDH})$ is a general indicator of the existence and severity of acute or chronic tissue damage and, sometimes, as a monitor of progressive conditions such as some cancers, kidney disease, and liver disease [26].

Our results showed no effect of Arabic coffee consumption on the LDH and Creatine kinase (CK) enzymes. Studies on the effect of coffee consumption on $\mathrm{CV}$ enzymes are scarce. Compatible with our results, two studies on coffee consumption showed no association with heart failure (HF).

A cohort study on 59,490 Finnish participants aged 25-74 years who were free of $\mathrm{HF}$ at baseline indicated that coffee consumption did not increase the risk of HF in both men and women. In women, an inverse association was observed between low to moderate coffee consumption and the risk of HF [27]. 
Table 3. Dose-Response effect of Cardamom in Arabic coffee on liver enzymes before and after intervention

\begin{tabular}{|c|c|c|c|c|c|}
\hline Group & $\begin{array}{c}\text { ALT } \\
(\mathbf{U} / \mathbf{L})\end{array}$ & $\begin{array}{c}\text { AST } \\
(\mathbf{U} / \mathbf{L})\end{array}$ & $\begin{array}{c}\text { TP } \\
(\mathrm{g} / \mathrm{dL})\end{array}$ & $\begin{array}{l}\text { GGT } \\
\text { (U/L) }\end{array}$ & $\begin{array}{c}\text { TBI } \\
(\mathrm{mg} / \mathrm{dl})\end{array}$ \\
\hline \multicolumn{6}{|l|}{ Control } \\
\hline Pre-intervention & $19.00 \pm 3.16$ & $15.57 \pm 5.38$ & $7.67 \pm 0.73$ & $34.14 \pm 20.21$ & $0.24 \pm 0.13$ \\
\hline Post-intervention & $22.00 \pm 6.73$ & $16.57 \pm 7.98$ & $7.89 \pm 0.47$ & $26.14 \pm 10.75$ & $0.24 \pm 0.17$ \\
\hline \multicolumn{6}{|l|}{ ACLC } \\
\hline Pre-intervention & $21.25 \pm 2.92$ & $14.88 \pm 5.82$ & $7.46 \pm 0.56$ & $36.63 \pm 7.46^{\mathrm{a}}$ & $0.23 \pm 0.12$ \\
\hline Post-intervention & $22.00 \pm 3.66$ & $14.50 \pm 4.21$ & $7.31 \pm 0.65$ & $30.13 \pm 4.52^{\mathrm{a}}$ & $0.19 \pm 0.06$ \\
\hline \multicolumn{6}{|l|}{ ACHC } \\
\hline Pre-intervention & $19.40 \pm \quad 3.50$ & $12.70 \pm 4.88$ & $7.77 \pm 1.01$ & $28.80 \pm 7.13^{\mathrm{b}}$ & $0.26 \pm 0.12$ \\
\hline Post-intervention & $19.90 \pm 1.85$ & $12.20 \pm 2.94$ & $7.48 \pm 0.45$ & $21.90 \pm 5.67^{\mathrm{b}}$ & $0.25 \pm 0.13$ \\
\hline
\end{tabular}

Results are expressed as mean \pm SD. Data are analyzed by Paired Comparison t-test. ${ }^{\mathrm{a}, \mathrm{b}}$ represent significant differences between post-treatment compared to pre-treatment at the level $(\mathrm{p} \leq 0.05)$ Abbreviations: ALT, alanine transaminase; AST, aspartate transaminase; TP, total protein; GGT, gamma glutamyl transpeptidase ; TBI, total bilirubin.

Table 4. Dose-Response effect of Cardamom in Arabic coffee on cardiovascular enzymes and inflammatory biomarker before and after intervention

\begin{tabular}{cccc} 
Group & $\begin{array}{c}\text { CRP } \\
\mathbf{m g} / \mathbf{d l}\end{array}$ & CKI & $\begin{array}{c}\text { LDH } \\
\text { U/L }\end{array}$ \\
Control & & & \\
Pre-intervention & $0.69 \pm 0.70$ & $71.71 \pm 32.63$ & $126.86 \pm 27.46$ \\
Post-intervention & $0.56 \pm 0.59$ & $75.86 \pm 30.73$ & $130.14 \pm 15.49$ \\
ACLC & & & $121.88 \pm 46.19$ \\
Pre-intervention & $0.81 \pm 0.55$ & $80.88 \pm 29.77$ & $142.88 \pm 32.07$ \\
Post-intervention & $1.03 \pm 0.78$ & $89.88 \pm 36.35$ & $116.40 \pm 32.57$ \\
ACHC & & & $127.30 \pm 17.57$ \\
Pre-intervention & $0.48 \pm 0.24$ & $49.30 \pm 15.26$ & $62.00 \pm 36.76$ \\
Post-intervention & $0.45 \pm 0.21$ & & \\
\hline
\end{tabular}

Data analyzed by paired comparison t-test at the level $(\mathrm{p} \leq 0.05)$. Data are expressed as mean \pm SD. Abbreviations: CRP, C-reactive protein; CKI, Creatine kinase; LDH, Lactate dehydrogenase. ACLC, Arabic coffee with low cardamom group; ACHC, Arabic coffee with high cardamom group.

Another cohort study on 34,551 Swedish women (48 -83) years old, who did not have heart failure, diabetes, or myocardial infarction at base line, found no association between coffee consumption and the incidence of HF [28].

In the last few decades scientists have shown that some antioxidants have anti-inflammatory properties. The presence of antioxidants in coffee has been shown to prevent free radicals from causing cell damage. Ingredients other than caffeine such as chlorogenic acid and caffeic acid are antioxidants in nature, and their presence slows down the process of inflammation, thereby providing protection from the hazardous effect of free radicals and against endothelial damage [29]. In our study, Arabic coffee consumption did not affect the subclinical biomarker of inflammation $\mathrm{C}$ - reactive protein (CRP). This could be because the study participants were healthy subjects who had normal levels of CRP, and no indications of inflammation.

As for the effect of Arabic coffee on Liver function, a beneficial effect was observed in the liver enzyme Gamma glutamyltranspeptidase (GGT). Gamma glutamyltranspeptidase (GGT) is the most sensitive indicator of hepatobiliary disease at present. Arabic coffee, with both doses of cardamom, was capable of reducing serum GGT compared with the non-cardamom coffee. The study of Onuegbu et al., (2011) [30] investigated the effect of coffee consumption on liver function in men and women consuming 2 grams of coffee daily for 30 days, indicated that short -term consumption of coffee might have a significant effect on the integrity of the liver function tests studied. Epidemiologically, coffee intake has been inversely related to the serum enzyme activities gamma-glutamyltransferase, and alanine aminotransferase (ALT) in studies performed in various countries [31]. A study on rats indicated that Arabic coffee caused a marked reduction in GGT, but did not alter the activities of the other enzymes ALP, ALT, AST [22]. 


\section{Conclusion}

According to the findings of this study, consumption of $(500 \mathrm{ml})$ of Arabic coffee with regular or high dose of cardamom (5 days/week) for four weeks showed no effect on blood pressure, or the inflammation biomarker CRP, or heart enzymes. In addition, a beneficial effect on liver function was shown in the reduction of serum GGT activity. However, an adverse effect was observed regarding lipid profile where increases in TC were observed in Arabic coffee with the low dose of cardamom, and in TC and LDL-C after consumption of Arabic coffee with the high dose of cardamom.

Since this study has been done on healthy subjects, it is recommended that healthy people consume less than $(500$ $\mathrm{ml} /$ day) Arabic coffee. Individuals with hyperlipidemia/CVD should limit their intake of Arabic coffee as it raises TC and LDL-C especially with a high dose of cardamom. Further studies are needed to determine the safe dose of Arabic coffee consumption on blood lipids and blood pressure in healthy and hypertensive subjects. Also, further studies are needed on the effect of various doses of cardamom alone on health, as well as the effect of Arabic coffee preparation concerning the level of roasting, brewing time, and level of coffee constituents (Caffeine, Chlorogenic acid, Kahewol, Cafestol). Filtering Arabic coffee might reduce the diterpenes that would raise cholesterol. Future Studies on consumption of filtered Arabic coffee should be explored and compared to the regular boiled coffee.

\section{Acknowledgments}

The authors are grateful to King Abdulaziz City of Science and Technology for their grant to conduct this study (D-S-12-0117). The authors would like to thank Emad Shororou, and Sara Salama for their technical support in blood collection and assays.

\section{References}

[1] M.S. Butt and M.T.Sultan. "Coffee and its Consumption: Benefits and Risks", Critical Reviews in Food Science and Nutrition, vol. 51, pp.363-73, 2011

[2] http://www.earthtrends.wri.org. (Last Accessed: 20/1/2013)

[3] S. Masten and R Tice. "Review of Toxicological Literature". Structure, vol.632, pp. 79-81, 1999

[4] S.H. Jee, J. He, and L.J.Appel. "Coffee consumption and serum lipids: A meta-analysis of randomized controlled clinical trials". Am J Epid., vol.153, pp.353-362, 2001

[5] W.C.Willett, M.J. Stampfer, and J.E. Manson. "Coffee consumption and coronary heart disease in women. A ten-year follow-up". JAMA., vol. 275, pp. 458-462, 1996

[6] A. Ascherio, S.M. Zhang, and M.A Hernan. "Prospective study of consumption an risk of Parkinson's disease in men and women". Annals of Neurology, vol. 50, pp.56-63, 2001

[7] A. Ascherio, E. Salazar-Martinez, and W.C Willett. "Coffee consumption and risk for type 2 diabetes mellitus". Annals Internal Medicine, vol.140, pp.1-8, 2004.

[8] M.C. Cornelis and A. El-Sohemy. "Coffee, caffeine, and coronary heart disease". Current opinion in clinical nutrition and metabolic Car. vol.10(6), pp.745-51, 2007

[9] S. Hamdan. "Effects of Supercritical Carbon Dioxide and Sub-critical Propane Extraction of Thyme and Cardamom on Chemical Composition, Antioxidant Capacity and Antimicrobial Properties". Central Food Research Institute, Budapest. 2008

[10] M. Polovka and M. Suhaj. "The Effect of Irradiation and Heat Intervention on Composition and Antioxidant Properties of Culinary Herbs and Spices - A Review". Food Reviews International, vol. 26, pp.138-161, 2010

[11] A. Acharya , I. Das, S. Singh, and T. Saha. "Chemopreventive properties of indole-3-carbinol, diindolylmethane and other constituents of cardamom against carcinogenesis". Recent Patents on food, nutrition\& agriculture., vol. 2, pp.166-77, 2010

[12] B.E. Statland and T.J. Demas. Serum caffeine half-lives. Healthy subjects vs. patients having alcoholic hepatic disease. Am J Clin Pathol. vol. 73(3), pp.390-3, 1980

[13] N.W. Tietz. "Specimen Collection and Processing; Sources of Biological Variation", Textbook of Clinical Chemistry, W.B. Saunders, Philadelphia, PA. pp. 478- 518, 1986

[14] L. Siekmann, F. Ceriotti, G. Ferard, T. Kanno, G. Schumann, et al. "IFCC Primary reference procedures for the measurement of catalytic activity concentrations of enzymes at 37 C. Part 2 .Reference procedure for measurement of catalytic concentrations of creatine kinase [ATP: creatine N-phosphoransfera (CK), EC 2.7.3.2]" Clinical Chemistry Lab Med., vol. 40(6), pp.635-642, 2002

[15] HU. Bergmeyer, P. Scheibe, and A.W. Wahlefeld. "Optimization of methods for aspartate aminotransferase and alanine aminotransferase". Clinical Chemistry, vol. 24(1), pp.58-73, 1978

[16] H.U. Bergmeyer, M. Horder, and D.W. Moss. "Provisional recommendations on IFCC methods for the measurement of catalytic concentrations of enzymes. Part 3. Revised IFCC method of aspartate aminotransferase (L-Aspartate:2oxoglutarate aminotransferase, EC 2.6.1.1.)". Clin Chem., vol. 24(4), pp. 720-721, 1977

[17] M.B Smith. "Equivalency of Serum and Plasma Test Results on 42 Methods on Dimension Clinical Chemistry System". Dade Behring, Newark, DE. 2001

[18] L.M. Shaw, J.H. Stromme, JL.London, and L. Theodorsen. "IFCC method for the determination of enzymes part 4 .IFCC method for gamma-glutamyl transferase [(gamma-glutamyl)-peptide; amino acid gamma-glutamyl transferase, EC 2.3.2.2]". Clinical Chimica Acta., 15F-338F, 1983.

[19] B.T. Doumas, B.W. Perry, E.A. Sasse, et al. "Standardization in bilirubin assays: Evaluation of selected method and stability of bilirubin solution" Clin Chem., vol.19, pp.984-993, 1973 
[20] M. P. M. E. Weusten-vanderWouw, M. B. Katan, R. Viani,, A.C. Huggett, R. Liardon, P. G. Lund-Larsen, D. S. Thelle, et al. "Identity of the coffee raising factor from boiled coffee and its effects on liver function enzymes". Journal of Lipid Research. vol. 35, pp.721-733, 1994

[21] R. Ugert, N. Esseol, G. Vander Weg , T. G. Kosmeiger-Schuil, and M.B. Katan. "Separate effects of the coffee diterpenescafestol and kahweol on serum lipids and liver transaminases". Am J Clin Nutr., vol. 65, pp. 519-524, 1997

[22] A.A. Al-Maghrabi . "Effect of Arabian coffee on lipids, homocysteine, glutathione and liver enzymes in rat serum". Master degree thesis, King Abdulaziz University, Jeddah. 2007

[23] L. Cai, D. Ma, Y. Zhang, Z. Liu, and P. Wang. "The effect of coffee consumption on serum lipids: a meta-analysis of randomized controlled trials"._Eur J Clin Nutr. Vol. 66(8). Pp.872-7, 2012

[24] F. Abd El-Razek and E. Sadeek. "The chemo-protective effect of Turmeric, Chili, Cloves and Cardamom on correcting iron overload-induced liver injury, oxidative stress and serum lipid profile in rat models". J Am Sci., vol. 6, pp.702-712, 2010

[25] A.E. Mesas, L.M. Leon-Muñoz, F. Rodriguez-Artalejo, and
E. Lopez-Garcia. "The effect of coffee on blood pressure and cardiovascular disease in hypertensive individuals: a systematic review and meta-analysis". Am J Clin Nutr., vol. 94, pp.1113-26, 2011.

[26] http://labtestsonline.org/understanding/analytes/ldh/tab/test (last accessed: 20/1/2013)

[27] Y. Wang, J. Tuomilehto, P. Jousilahti, R. Antikainen, M. Mähönen, S. Männistö, et al. "Coffee consumption and the risk of heart failure in Finnish men and women". Heart (British cardiac society), vol. 97, pp. 44 -8, 2011.

[28] EB. Levitan, H.N. Ahmed, M.A. Mittleman, and A.Wolk . "Coffee consumption and incidence of heart failure in women". Circulation.vol. 4, pp. 414-8, 2011.

[29] E. Lopez-Garcia, R.M. van Dam, L. Qi, and F.B. Hu. "Coffee consumption and markers of inflammation and endothelialdys function in healthy and diabetic women1-3". Am J Clin Nutr., vol. 84, pp.888-93, 2006

[30] A.J. Onuegbu, J.M. Olisekodiaka, O.E Adebolu, A. Adesiyan, and O.E. Ayodele. "Coffee consumption could affect the activity of some liver enzymes and other biochemical parameters in healthy drinkers, Medical principles and practice”. Int J Kuwait Univ., vol. 20, pp.514-8, 2011

[31] P. Muriel and J. Arauz. "Coffee and liver diseases". Fitoterapia., vol. 81, pp. 297-305, 2010 